\title{
Desenvolvimento fenológico de frutos de lichia (Litchi chinensis) em diferentes regiões
}

\section{Phenological development litchi fruit (Litchi chinensis) in different regions} \author{
Denis H. S. Nadaleti e Bianca A. Machado 5 \\ ${ }_{1}^{1}$ Universidade Estadual Paulista (UNESP), Departamento de Horticultura, Botucatu-SP, CEP: 18610 - 307, Brasil \\ ${ }_{2}^{2}$ Instituto Federal de Ciência Educação e Tecnologia do Sul de Minas Gerais, Muzambinho-MG, CEP: 37890-000, Brasil \\ 3 Universidade Estadual Paulista (UNESP), Departamento de Ciências Exatas, Jaboticabal-SP, CEP - 14884-900, Brasil \\ 4 Universidade Federal de Lavras, Departamento de Agricultura, Lavras-MG, CEP 37200-000, Brasil \\ 5 Escola Superior de Agricultura “Luiz de Queiroz" Departamento de Ciência do Solo Piracicaba-SP, CEP 13418-900, Brasil \\ ( ${ }^{\star} E$-mail:aprigio_bibiano@hotmail.com) \\ http://dx.doi.org/10.19084/RCA16035 \\ Recebido/received: 2016.03.15 \\ Recebido em versão revista/received in revised form: 2016.11.18 \\ Aceite/accepted: 2016.11.22
}

Rafael B. Ferreira1,*, Bianca S. de Souza², Paulo S. de Souza², Lucas E. O. Aparecido³,

\section{R E S U M O}

Avaliou-se o desenvolvimento fenológico de frutos da lichieira em duas regiões diferentes do Brasil, sendo uma em Casa Branca-SP e outra em Monte Belo-MG. As avaliações foram realizadas quinzenalmente, tendo início a partir do vingamento dos frutos e seguindo até o ponto de maturação fisiológica dos respectivos locais. Foram realizadas as seguintes avaliações: número de frutos por inflorescência, diâmetro longitudinal e transversal, matéria fresca e seca dos frutos, teor de sólidos solúveis e acidez titulável dos frutos. A abscisão dos frutos em Casa Branca foi constante até 28 dias do vingamento, com perda de aproximadamente $46 \%$ dos frutos. Em Monte Belo a perda foi constante durante todo o período de avaliação, sem que houvesse estabilização deste parâmetro. A acumulação de matéria seca no início das avaliações foi lenta em ambos os locais, passando a acelerar respectivamente após os 28 e 27 dias do vingamento. No ponto de maturação fisiológica, as plantas de Casa Branca apresentaram um número médio de 10 frutos por inflorescência a mais do que as plantas de Monte Belo. Em ambos os locais, os frutos levaram cerca de 12 semanas após o vingamento para chegarem ao estádio de maturação fisiológica.

Palavras-chave: Litchi chinensis, estádios de maturação, maturação comercial.

\begin{abstract}
It was evaluated the phenological development of litchi fruit in two different climatic conditions in Brazil, one in the Casa Branca-SP and another in Monte Belo-MG. Evaluations were made fortnightly, starting from the fruit set and continuing until the physiological maturity of the respective sites. The following evaluations were assessed: number of fruits per inflorescence, the longitudinal and transversal diameter, fresh and dry fruits, total soluble solids and titratable acidity of the fruit. The abscission of fruits in the Casa Branca was constant up to 28 days of fixation, with a loss of approximately $46 \%$ of the fruit. Monte Belo loss was constant throughout the period of evaluation, without stabilization of this parameter. The dry matter accumulation at the beginning of the evaluations was slow in both places, accelerating respectively after 28 and 27 days of fixation. At physiological maturity, Casa Branca plants had an average of 10 fruits per inflorescence more than Monte Belo plants. In both locations, the fruits took about 12 weeks after fruit set to reach the physiological maturity.
\end{abstract}

Keywords: Litchi chinensis, maturation stages, commercial maturity.

\section{INTRODUÇÃO}

A lichieira (Litchi chinensis Soon.) é uma fruteira de clima subtropical pertencente à família Sapindaceae (Jiang et al., 2012) de origem chinesa
(Dembitsky et al., 2011). O seu ciclo pode ser separado em sete estádios, sendo eles: abrolhamento, aparecimento das folhas, desenvolvimento da parte aérea, aparecimento da inflorescência, 
floração, desenvolvimento dos frutos e maturação (Wei et al., 2013).

É uma planta arbórea, que pode alcançar 10 a 12 metros de altura, com inflorescências em forma de panícula, com flores brancas que se desenvolvem entre o final do inverno e início da primavera, durante os meses de agosto e setembro, a partir do abrolhamento dos ramos do ano (Martins, 2005). Em função da cultivar e do ambiente cada panícula pode emitir até 4000 flores (Wei et al., 2013), podendo ser masculinas, parcialmente masculinas ou parcialmente femininas (Stern and Gazit, 2003).

No início do desenvolvimento, os frutos possuem coloração verde, contudo, conforme o processo de maturação acontece ocorre também a degradação da molécula de clorofila e a síntese de antocianinas (Wang et al., 2007), conferindo coloração avermelhada aos frutos (Kumar et al, 2012). Além da coloração característica, quando chegam ao seu estádio de maturação fisiológica, os frutos da lichieira apresentam forma arredondada, tendo uma única semente em seu interior, contendo polpa translúcida, suculenta, de sabor adocicado e muito nutritiva (Dembitsky et al., 2011).

O considerável retorno econômico obtido pela comercialização dos frutos (Liang et al., 2013) confere grande importância à planta em países como China, Índia, Vietname e Tailândia (Olesen et al., 2013), sendo os dois primeiros os maiores produtores mundiais (Pandey et al., 2013).

A constante busca da população por uma melhor qualidade de vida através de uma alimentação mais saudável e nutritiva (Queiroz et al., 2012) tem proporcionado aumento do consumo de frutos como a lichia, gerando o interesse de outros países na sua produção, como por exemplo, o Brasil.

Devido às condições climáticas, o Brasil pode ser considerado como promissor para o cultivo desta fruteira. Todavia, o país ainda possui certas limitações na sua produção devido à falta de pesquisas e tecnologias de produção, proporcionando baixo rendimento aos pomares. A ampliação deste conhecimento é de muita importância, podendo assim não apenas elevar a produtividade dos pomares como também aumentar a rentabilidade da cultura.
Uma compreensão exata dos estádios de desenvolvimento dos frutos é muito importante para uma condução correta do pomar, particularmente no controlo de pragas e doenças, na rega, na retenção dos frutos, controlo do abrolhamento, nas fertilizações e na aplicação de reguladores de crescimento de plantas (Wei et al., 2013).

$\mathrm{Na}$ literatura não foram encontrados trabalhos que descrevam o desenvolvimento fenológico dos frutos de lichia na região de interesse, pelo que se objetivou por meio deste trabalho caracterizar o desenvolvimento fenológico de frutos da lichieira nas localidades de Casa Branca, SP e Monte Belo, MG.

\section{MATERIAIS E MÉTODOS}

O trabalho foi realizado nos municípios de Casa Branca-SP $\left(21^{\circ} 47^{\prime} \mathrm{S}\right.$ e $47^{\circ} 06^{\prime} \mathrm{O}$ e 702 metros de altitude), e a classificação climática segundo Thornthwaite (1948) é B2rB'3a'e no município

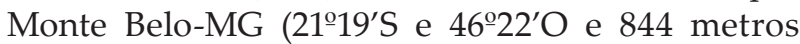
de altitude), que possui classificação climática segundo Thornthwaite (1948) B4rB'2a (Rolim e Aparecido, 2015).

O ensaio foi desenvolvido no período de agosto de 2012 a janeiro de 2013. Durante sua implantação foram selecionadas 10 plantas de lichieiras 'Bengal' dentre as demais da propriedade e marcadas. Posteriormente foram sorteados aleatoriamente três ramos com inflorescência em cada uma das 10 plantas. A partir do vingamento dos frutos (15 dias após a data da marcação) foram realizadas quinzenalmente até atingirem o ponto de maturação comercial, as seguintes avaliações: contagem de todos os frutos de cada ramo nas respectivas plantas, medição dos diâmetros transversal e longitudinal de três frutos por ramo. Posteriormente, foram colhidos três frutos por planta, que foram transportados até o laboratório de Bromatologia e Água do Instituto Federal de Ciência Educação e Tecnologia doSul de Minas-Campus Muzambinho para a realização de análises de matéria fresca e seca. Ao atingirem a maturação fisiológica, os frutos foram desmembrados em pericarpo, arilo e semente para realização de análise de sua matéria fresca e seca separadamente. Após uma verificação visual de que os frutos já possuíam polpa, foram 
feitas além das análises físicas mencionadas anteriormente, análises químicas: teor de sólidos solúveis e acidez titulável, para cada uma das plantas.

Os métodos utilizados para estas análises foram: matéria fresca dos frutos: determinada através de balança com capacidade para $1200 \mathrm{~g}$ e precisão de 0,1 g; matéria seca: com o auxílio de estufa de circulação forçada a $65^{\circ} \mathrm{C}$; diâmetro transversal (DT) e longitudinal (DL): com o auxílio de uma craveira, em milímetros; relação polpa: semente: pericarpo: através da determinação da massa da polpa, da semente e do pericarpo; teor de sólidos solúveis (SS) foi determinado em refratômetro digital (Atago PR 101) e os resultados expressos em ${ }^{\circ}$ Brix (AOAC, 2012); acidez titulável expressa em gramas de ácido málico por $100 \mathrm{~g}$ de polpa. Cada amostra de $10 \mathrm{~g}$ de polpa homogeneizada foi titulada com solução padronizada de hidróxido de sódio a 0,1 M, até a amostra alcançar pH 8,1 (AOAC, 2012).

Os dados foram analisados por meio de estatística descritiva, onde cada valor representa as médias de todos os valores obtidos em cada avaliação.

\section{RESULTADOS E DISCUSSÃO}

As análises em Casa Branca tiveram início no dia 24 de setembro de 2012 e seguiram até o dia 17 de dezembro, aos 84 dias do vingamento enquanto que em Monte Belo as avaliações iniciaram no dia 9 de outubro de 2012 e seguiram até o dia 3 de janeiro de 2013, 85 dias após o vingamento quando os frutos chegaram à maturação fisiológica. Em ambas as localidades, o desenvolvimento dos frutos de lichia durou 12 semanas, estando próximo aos dois meses e meio relatados por Wei et al. (2013). As diferenças observadas entre as datas do pegamento e da colheita indicaram adiantamento no desenvolvimento dos frutos da Casa Branca.

O número médio de frutos por inflorescência teve acentuado decréscimo ao longo do ensaio em ambos os locais analisados. Em Casa Branca as maiores perdas ocorreram 28 dias após o vingamento, onde foram contabilizadas perdas de cerca de $46 \%$ no número de frutos (Figura 1A). Ocorreram poucas perdas a partir desta data até o final do ensaio, sendo que o número médio de frutos passou de 29,15 em 22 de outubro para 23,97 em 17 de dezembro, indicando uma quebra de 17\% neste parâmetro. Salomão et al. (2006), relatam que na cultivar 'Bengal' embora a queda dos frutos da lichieira ocorra durante todo o seu desenvolvimento, as perdas mais significativas ocorrem no mês de outubro, que correspondente à etapa inicial do seu desenvolvimento.

A abscisão em Monte Belo foi constante durante todo o período de avaliação, obtendo perdas de aproximadamente $40 \%$ do início das avaliações até 41 dias do vingamento (Figura 1B). Neste período, a média de 32 frutos caiu para 19,03. Durante a colheita comercial estes valores diminuíram ainda mais, apresentando uma média de 13 frutos por inflorescência. Santos et al. (2009) relatam que
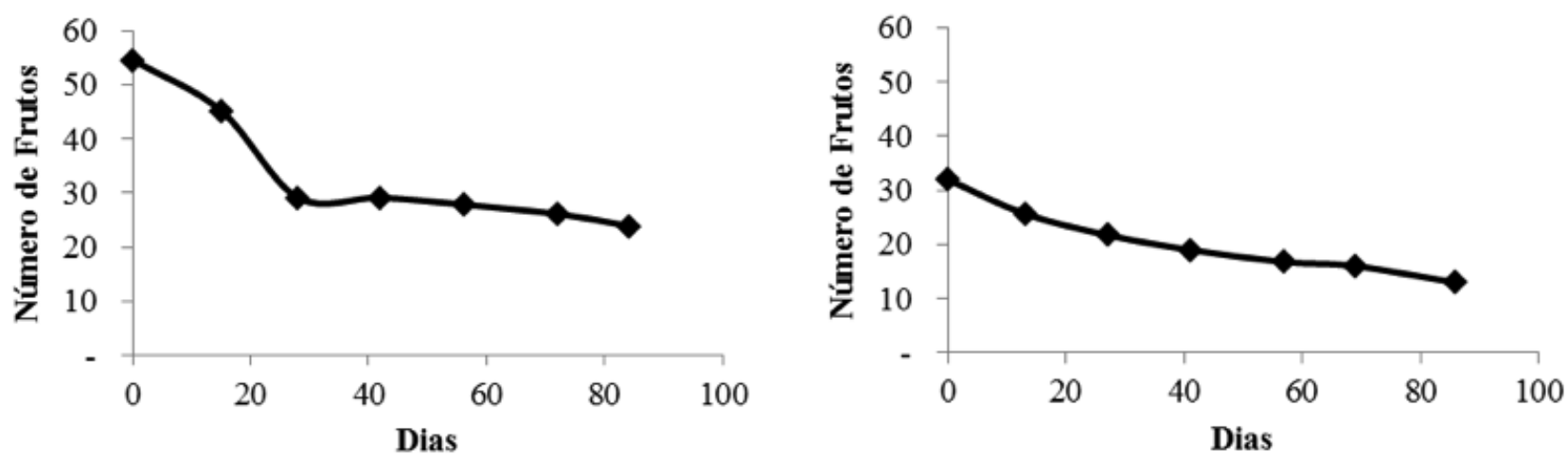

Figura 1 - Número médio de frutos de lichia por inflorescência em Casa Branca-SP (A) e em Monte Belo-MG (B) (IFSULDEMINAS - Campus Muzambinho, 2012/2013). 
as lichieiras que não receberam nenhum tipo de tratamento (controlo), apresentaram uma média de 17 frutos por inflorescência, valor este que está próximo ao encontrado neste trabalho.

Os dados obtidos indicam que independentemente do dia de avaliação, o número médio dos frutos na Casa Branca foi sempre superior aos de Monte Belo, inclusive durante a colheita comercial. Contudo, salienta-se que a menor quantidade de frutos apresentada em Monte Belo em relação à Casa Branca pode ter sido influenciada pela presença do ácaro Aceria litchii (Keifer) (Eriophyidae), também chamado de ácaro da erinose.

A matéria fresca média dos frutos em ambos os locais avaliados aumentou de forma intensa durante todo o ensaio, tendo valores de $0,51 \mathrm{~g}$ na Casa Branca e de 0,13 g para Monte Belo aos 15 dias após o vingamento (Figura 2). Nesta época os frutos possuíam respectivamente 0,17 (34,35\%) e $0,04(26,37 \%)$ g de matéria seca em média. Para a lichieira 'Shahi', Khalkho et al. (2015), verificaram que o aumento em massa dos frutos foi lento até 35 dias do início da frutificação, intensificando-se após este período até á maturação fisiológica. Diferenças em relação aos padrões de desenvolvimento dos frutos podem ser encontradas em função da cultivar avaliada.

No ponto de maturação fisiológica, os frutos de lichia em Casa Branca apresentaram 23,88 g de matéria fresca, sendo que $25,76 \%$ deste peso $(6,15 \mathrm{~g})$ representava a matéria seca média (Figura $2 \mathrm{~A}$ ).
Em Monte Belo os valores de matéria fresca média chegaram a 21,44 g na maturação fisiológica, possuindo $25 \%$ de matéria seca (5,36 g) (Figura 2B). Santos et al. (2009), encontraram valores médios de matéria fresca entre 20,08 e 21,57 g nos testes com diferentes tipos de monda de frutos no desenvolvimento da lichia, valores estes próximos aos encontrados neste trabalho.

O aumento da matéria seca nos frutos foi lento até o fim de outubro aos 28 dias do vingamento na Casa Branca, e aos 27 dias em Monte Belo, no início de novembro. Esta acumulação lenta durante o início do desenvolvimento dos frutos deu-se devido à presença de muitos frutos por inflorescências (Figura 3), o que gera competição entre estes (Salomão et al., 2006).

Foi observado neste trabalho que na Casa Branca a acumulação de matéria seca foi coincidente com o período em que a queda dos frutos se estabilizou. A menor quantidade de frutos por inflorescência após este período proporcionou melhor distribuição de metabólitos pela planta, deixando os frutos mais vigorosos. A mesma relação não foi observada em Monte Belo, já que nesta o número médio de frutos por inflorescência continuou diminuindo consideravelmente até á colheita, o que pode ser justificado pela presença do ácaro Aceria litchii no local.

Para as proporções entre a semente, pericarpo e arilo durante o estádio de maturação fisiológica dos frutos, Casa Branca apresentou relações de
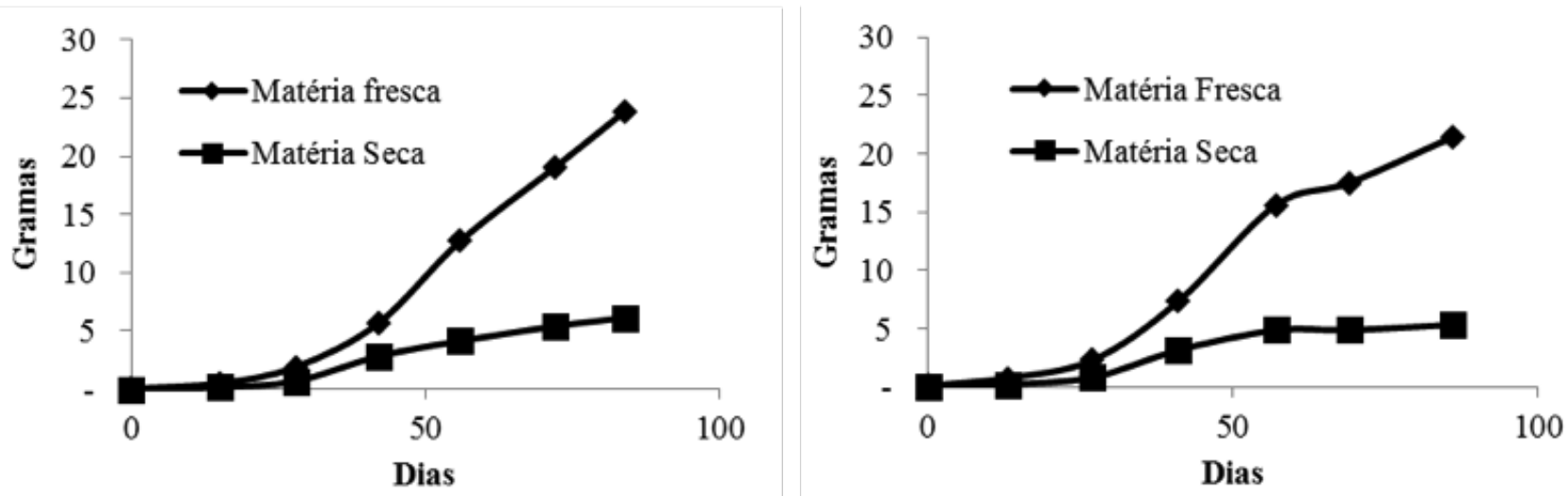

Figura 2 - Matéria fresca e seca dos frutos de lichia em Casa Branca-SP (A) e em Monte Belo-MG (B) (IFSULDEMINAS - Campus Muzambinho, 2012/2013). 

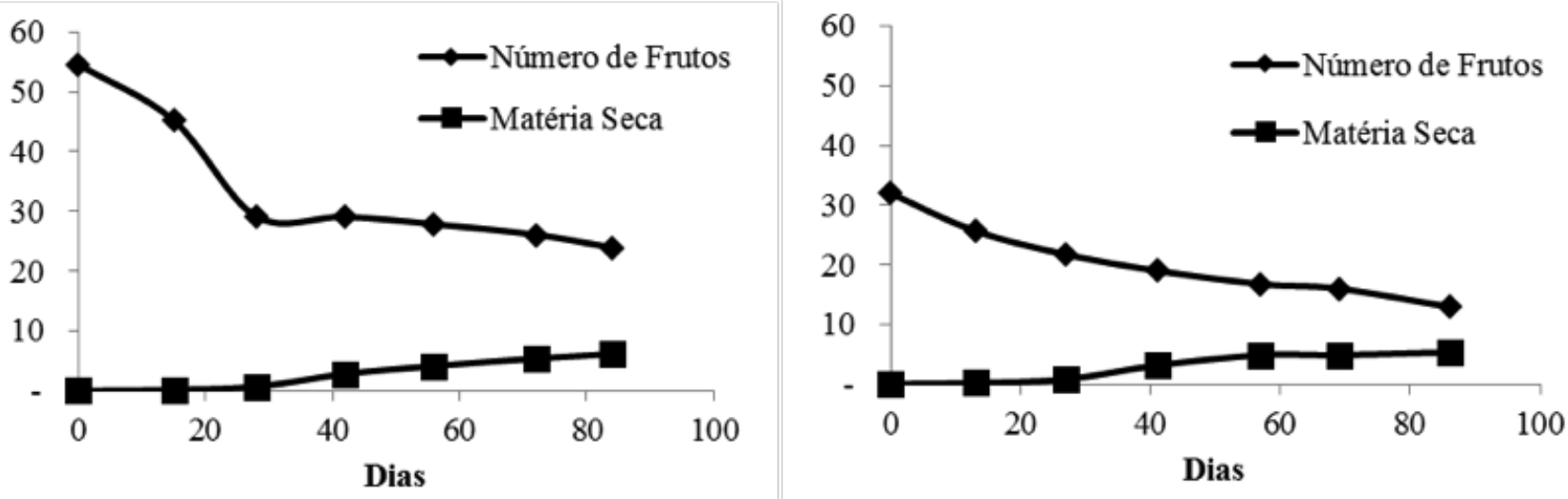

Figura 3 - Relação entre o número médio de frutos por inflorescência e o aumento da matéria seca em Casa Branca-SP (A) e em Monte Belo-MG (B) (IFSULDEMINAS - Campus Muzambinho, 2012/2013).

respectivamente $15,99 \%, 21,04 \%$ e $62,97 \%$ nos frutos frescos. Em relação à matéria seca, a distribuição do peso era dividida em $33,24 \%$ para semente, $20,96 \%$ para o pericarpo e $45,80 \%$ para o arilo. Em Monte Belo não foram encontradas muitas variações em relação às proporções apresentadas. A semente representava $16 \%$, o pericarpo $22,94 \%$ e o arilo $61,06 \%$ do peso fresco dos frutos. Na matéria seca foram encontradas distribuições de respectivamente $33,61 \%$, $23,87 \%$ e $42,52 \%$.

Os valores encontrados em relação aos pesos frescos não variam em relação aos encontrados por Salomão et al. (2006), em que as sementes dos frutos apresentavam $15,3 \%$, o arilo $59,7 \%$ e o pericarpo $24,9 \%$. Nos seus trabalhos, com a cultivar 'Logan', Jesus et al. (2008) encontraram uma proporção de $70,5 \%$ de arilo em relação aos frutos, relatando ainda que a semente representava apenas $8 \%$ do seu peso fresco.

Wei et al. (2013) retratam que o desenvolvimento dos frutos de lichia pode ser dividido em três fases: a primeira é caracterizada pelo desenvolvimento da semente, do pericarpo e do embrião; durante a segunda, acelera-se o desenvolvimento embrionário e inicia-se o crescimento do arilo, enquanto na terceira, o arilo apresenta um rápido crescimento e o processo de maturação acontece.

Tais características foram bem observadas em ambos os locais avaliados, onde o diâmetro longitudinal dos frutos aumentou constantemente até um determinado ponto que ao ser ultrapassado desacelerou de forma considerável o crescimento neste sentido, porém sem ser completamente paralisado (Figura 4). Esta fase caracteriza o desenvolvimento da casca, da semente e o inicio do crescimento do arilo dos frutos. A velocidade e a forma de desenvolvimento dos frutos em diâmetros longitudinais e transversais foram bem semelhantes tanto na Casa Branca como no Monte Belo. Em geral, a principal diferença observada foi em relação à data em que cada um chegou aos seus valores máximos, verificando-se um adiantamento dos frutos na Casa Branca em relação a Monte Belo.

O padrão de desenvolvimento longitudinal citado ocorreu do início das avaliações de cada um dos locais até aos 56 dias do vingamento na Casa Branca, onde os frutos passaram de $11,48 \mathrm{~mm}$ para $33,43 \mathrm{~mm}$ (Figura 4A) e para Monte Belo, onde os frutos passaram de $9,23 \mathrm{~mm}$ para $33,89 \mathrm{~mm}$, aos 57 dias do vingamento (Figura 4B). Não houve grandes diferenças entre o diâmetro longitudinal dos frutos em Casa Branca e Monte Belo nas respectivas datas de colheita, sendo que os valores médios encontrados foram de $35,49 \mathrm{~mm}$ no primeiro e de 34,94 no segundo. Santos et al. (2009), encontraram diâmetros longitudinais entre 37,67 e 38,27 mm durante as avaliações em lichias maduras.

Ainda na Figura 4, observa-se que em Casa Branca os frutos encontravam-se com uma média de $4,93 \mathrm{~mm}$ em diâmetro transversal no início do ensaio, aumentando para 17,94 $\mathrm{mm}$ aos 42 dias do vingamento e expandindo-se ainda mais na última avaliação, chegando a 29,13 mm em média. 

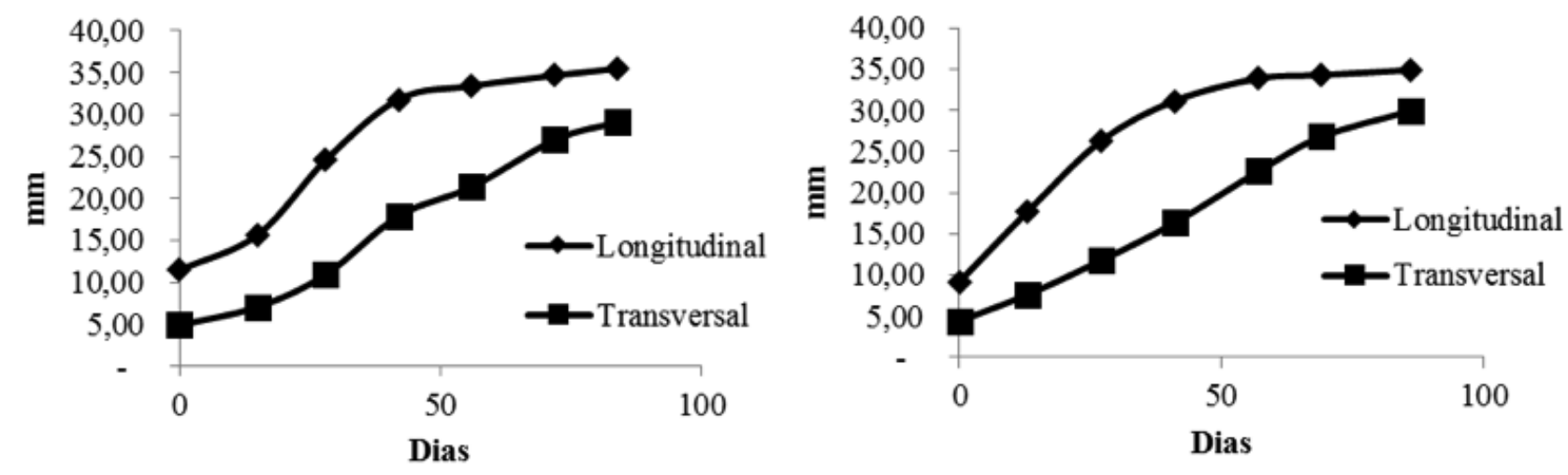

Figura 4 - Diâmetros longitudinais e transversais em Casa Branca-SP (A) e em Monte Belo-MG (B) (IFSULDEMINAS - Campus Muzambinho, 2012/2013).

Nos primeiros dias de avaliação em Monte Belo os frutos apresentavam valores médios de diâmetro de $4,44 \mathrm{~mm}$, chegando a $16,36 \mathrm{~mm}$ aos 41 dias do vingamento e a $29,97 \mathrm{~mm}$ nas últimas análises. Segundo Salomão et al. (2006), o crescimento da polpa é a principal característica responsável pelo crescimento dos frutos no sentido transversal. Os valores encontrados aquando da colheita comercial dos frutos foram inferiores aos encontrados por Santos et al. (2009), que descreveu valores de diâmetros transversais entre 30,39 e 33,17 mm.

Somboonkaew e Terry (2010) nos seus trabalhos com as cultivares 'Kom' e 'Mauritius' constataram que de entre os hidratos de carbono presentes nos frutos, a sacarose, a frutose e a glicose foram os mais abundantes. As diferenças entre a proporção destes açúcares são resultado de diferenças da atividade de invertases, maturação e cultivar. Como pode ser observado nas Figuras 5 e 6, durante a maturação dos frutos, os teores de sólidos solúveis aumentaram e a acidez titulável diminuiu. Esta diminuição é devido á sua transformação em açúcares ou à sua utilização como substrato no processo respiratório durante a maturação.

Os ácidos mais abundantes encontrados no arilo são o málico e o tartárico, porém também pode ser identificada a presença dos ácidos oxálico, cítrico e ascórbico (Somboonkaew e Terry, 2010). À medida que diminui a concentração do ácido o fruto torna-se mais doce devido à acidez influenciar menos na percepção da doçura. Muitas vezes a doçura do fruto está "mascarada" devido à alta concentração do ácido, sendo necessário baixar a acidez para que se possa perceber a doçura do fruto.

Na Casa Branca (Figura 5) os valores médios de acidez foram de 0,49 e 0,17 g de ácido málico $100 \mathrm{~g}$ polpa $^{-1}$ respectivamente para 72 e 84 dias após o vingamento dos frutos enquanto que para os sólidos solúveis se obtiveram valores de 14,45; 18,13 e $18,31^{\circ}$ Brix para os mesmos períodos. Já em Monte Belo (Figura 6), os valores médios de acidez foram de 0,66; 0,38 e 0,14 g de ácido málico $100 \mathrm{~g} \mathrm{polpa}^{-1}$ respectivamente para 56,68 e 86 dias após o vingamento dos frutos enquanto que para os sólidos solúveis se obtiveram valores de 17,05; 17,84 e $18,27^{\circ}$ Brix para os mesmos períodos.

Os valores de sólidos solúveis encontrados neste ensaio estão de acordo com os relatados por Perez e Martins (2006) para o município de Taquaritinga-SP que variaram entre 17,75 e $19,33^{\circ}$ Brix em função dos diferentes tratamentos avaliados e os de acidez titulável estão próximos aos encontrados por Santos et al. (2009) que obteve valores variando de 0,483 até $0,5338 \mathrm{~g}$ de ácido málico $100 \mathrm{~g} \mathrm{polpa}^{-1}$ na colheita.

\section{CONCLUSÕES}

O tempo de desenvolvimento dos frutos, do vingamento até á maturação fisiológica, foi semelhante em ambos os locais, porém observou-se a antecipação no início do desenvolvimento e da maturação dos frutos de lichia no município de Casa Branca-SP em relação a Monte Belo-MG. 


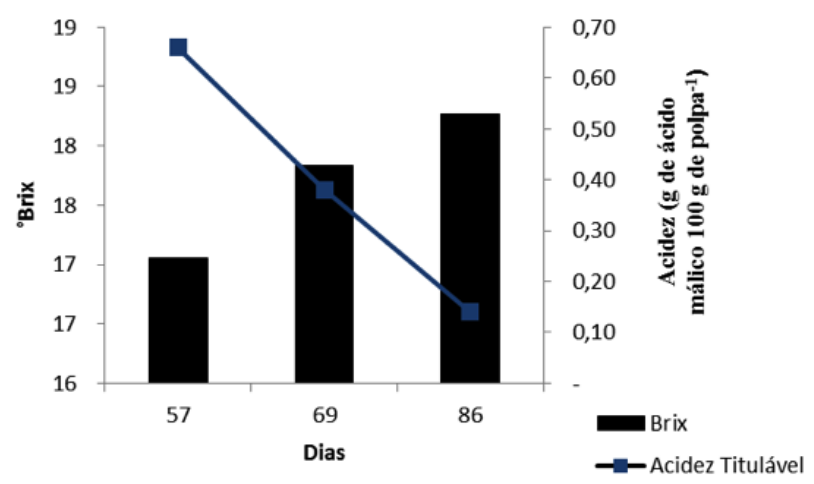

Figura 5 - Teor de sólidos solúveis e acidez titulável para frutos de lichia em Casa Branca-SP (IFSULDEMINAS - Campus Muzambinho, 2012/2013).

Ao Sr. Tadeu Sequaline, proprietário do sítio localizado no município de Monte Belo MG e aos proprietários do Sítio da Vovó, em Casa Branca SP e seu responsável Léo, por permitirem o desenvolvimento do presente trabalho nas suas propriedades.

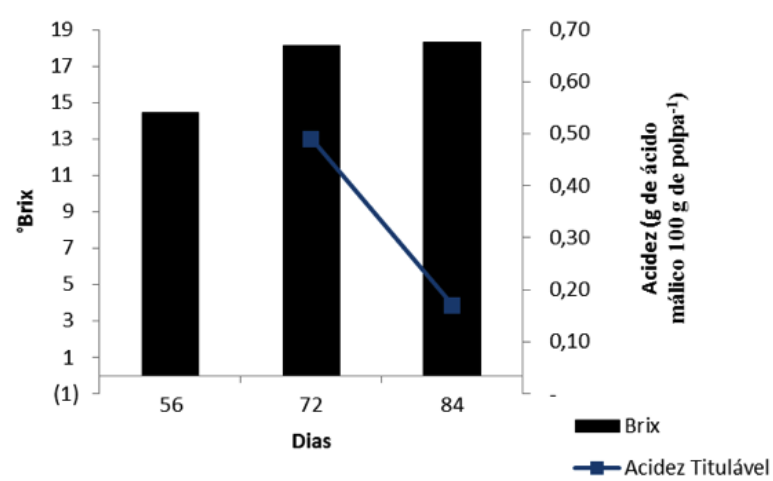

Figura 6 - Teor de sólidos solúveis e acidez titulável para frutos de lichia em Monte Belo-MG (IFSULDEMINAS - Campus Muzambinho, 2012/2013).

Também ao Instituto Federal de Ciência Educação e Tecnologia do Sul de Minas Gerais - Campus Muzambinho, pela bolsa de pesquisa e apoio durante a execução do trabalho.

\section{REFERÊNCIAS BIBLIOGRÁFICAS}

AOAC. (2012) - Official methods of analysis. 19th ed. Association of Official Analytical Chemistry. Gaithersburg, $3000 \mathrm{p}$.

Dembitsky, V.M.; Poovarodom, S.; Leontowicz, H.; Leontowicz, M.; Vearasilp, S.; Trakhrenberg, S. \& Gorinstein, S. (2011) - The multiple nutrition properties of some exotic fruits: Biological activity and active metabolites. Food Research International, vol. 44, n. 7, p. 1671-1701. http://dx.doi.org/10.1016/.jfoodres.2011.03.003

Jesus, N.; Martins, A.B.G. \& Barbosa, J.C. (2008) - Raleio de Frutos em Lichieira. Revista Brasileira de Fruticultura, vol. 30, p. 159-164.

Jiang, S.; Xu, H.; Wang, H.; Hu, G.; Li, J.; Chen, H. \& Huang, X. (2012) - A comparison of the costs of flowering in 'Feizixiao' and 'Baitangying' litchi. Scientia Horticulturae, vol. 148, p. 118-125. http://dx.doi. org/10.1016/j.scienta.2012.09.035

Khalkho, N.S.; Horo, P. \& Jha, K.K. (2015) - Effect of girdling and defoliation on physical proprieties of litchi fruit. Journal Crop and Weed, vol.11, n. 1, p. 200-203.

Kumar, S.; Mishra, B.B.; Saxena, S.; Bandyopadhyay, N.; More, V.; Wadhawan, S.; Hajare, S.N.; Gautan, S. \& Sharma, A. (2012) - Inhibition of pericarp browning and shelf life extension of litchi by combination dip treatment and radiation processing. Food Chemistry, vol. 131, n. 4, p. 1223-1232. http://dx.doi.org/10.1016/j. foodchem.2011.09.108

Liang, Y.S.; Wongmetha, O.; Wu, P.S. \& Ke, L.S. (2013) - Influence of hydrocooling on browning and quality of litchi cultivar Feizixiao during storage. International Journal of Refrigeration, vol. 36, n. 3, p. 1173-1179. http://dx.doi.org/10.1016/j.ijrefrig.2012.11.007

Martins, A.B.G. (2005) - Lichia. Revista Brasileira de Fruticultura, vol. 27, n. 3, p. 349-520. http://dx.doi.org/10.1590/ $\underline{\text { S0100-29452005000300001 }}$

Olesen, T.; Menzel, C.M.; McConchie, C.A. \& Wiltshire, N. (2013) - Pruning to control tree size, flowering and production of litchi. Scientia Horticulturae, vol. 156, p. 93-98. http://dx.doi.org/10.1016/j.scienta.2013.03.013

Pandey, N.; Joshi, S.K.; Singh, C.P.; Kumar, S.; Rajput, S. \& Khandal, R.K. (2013) - Enhancing shelf life of litchi (Litchi chinensis) fruit through integrated approach of surface coating and gamma irradiation. Radiation Physics and Chemistry, vol. 85, p. 197-203. http://dx.doi.org/10.1016/j.radphyschem.2012.11.003 
Pérez, E.G \& Martins, A.B.G. (2006) - Florescimento e frutificação de lichieiras em função do anelamento de ramos. Revista Brasileira de Fruticultura, vol. 28, n. 1, p. 14-17. http://dx.doi.org/10.1590/S0100-29452006000100007

Queiroz, E.R.; Abreu, C.M.P. \& Oliveira, K.S. (2012) - Constituintes Químicos das frações de lichia in natura e submetidas à secagem: potencial nutricional dos subprodutos. Revista Brasileira de Fruticultura, vol. 34, n. 4, p. 1174-1179. http://dx.doi.org/10.1590/S0100-29452012000400026

Rolim, G.S., Camargo, M.B.P.; Lania, D.G. \& Moraes, J.F.L. (2007) - Classificação climática de Köppen e de Thornthwaite e sua aplicabilidade na determinação de zonas agroclimáticas para o estado de São Paulo. Bragantia, vol. 66, n. 4, p. 711-720. http://dx.doi.org/10.1590/S0006-87052007000400022

Salomão, L.C.C; Siqueira, D.L \& Pereira, M.E.C. (2006) - Desenvolvimento do fruto da Lichieira (Litchi chinensis Sonn.) 'Bengal'. Revista Brasileira de Fruticultura, vol. 28, n. 1, p. 11-13. http://dx.doi.org/10.1590/ S0100-29452006000100006

Santos, C.E.M.; Silva, J.O.C.; Cavatte, R.P.Q.; Salomão, L.C.C. \& Bruckner, C.H. (2009) - Raleio de Frutos em Lichieira 'Bengal'. Revista Brasileira de Fruticultura, vol. 31, n. 2, p. 588-592. http://dx.doi.org/10.1590/ $\underline{\text { S0100-29452009000200038 }}$

Somboonkaew, N. \& Terry, L.A. (2010) - Altered physiology and biochemistry of imported litchi fruit held under different vapor pressure deficits. Journal of Agricultural and Food Chemistry, vol. 58, n. 10, p. 6209-6218. http://dx.doi.org/10.1021/if100023x

Stern, R.A. \& Gazit, S. (2003) - The reproductive biology of lychee. Horticultural Reviews, vol. 28, p. 393-453. http://dx.doi.org/10.1002/9780470650851.ch8

Wang, H.C.; Huang, H.B. \& Huang, X.M. (2007) - Different effects of abscisic acid and ethylene on the fruit maturation of Litchi chinensis Sonn. Plant Growth Regulation, vol. 52, n. 3, p. 189-198. http://dx.doi.org/10.1007/ $\underline{s 10725-007-9189-8}$

Wei, Y.Z.; Zhang, H.N.; Li, W.C.; Xie, J.H; Wang, Y.C; Liu, L.Q. \& Shi, S.Y. (2013) - Phenological growth stages of lychee (Litchi chinensis Sonn.) using the extended BBCH-scaleY. Scientia Horticulturae, vol. 161, p. 273-277. http://dx.doi.org/10.1016/j.scienta.2013.07.017 